\title{
Airvolt Aircraft Electric Propulsion Test Stand
}

\author{
Aamod Samuel ${ }^{1}$ and Yohan Lin $^{2}$ \\ NASA Armstrong Flight Research Center, Edwards, CA 93523-0273
}

\begin{abstract}
Development of an electric propulsion test stand that collects high-fidelity data of motor, inverter, and battery system efficiencies; thermal dynamics; and acoustics independent of manufacturer reported values will improve understanding of electric propulsion systems to be used in future aircraft. A buildup approach to this development reveals new areas of research and best practices in testing, and attempts to establish a standard for testing these systems.
\end{abstract}

\section{Nomenclature}

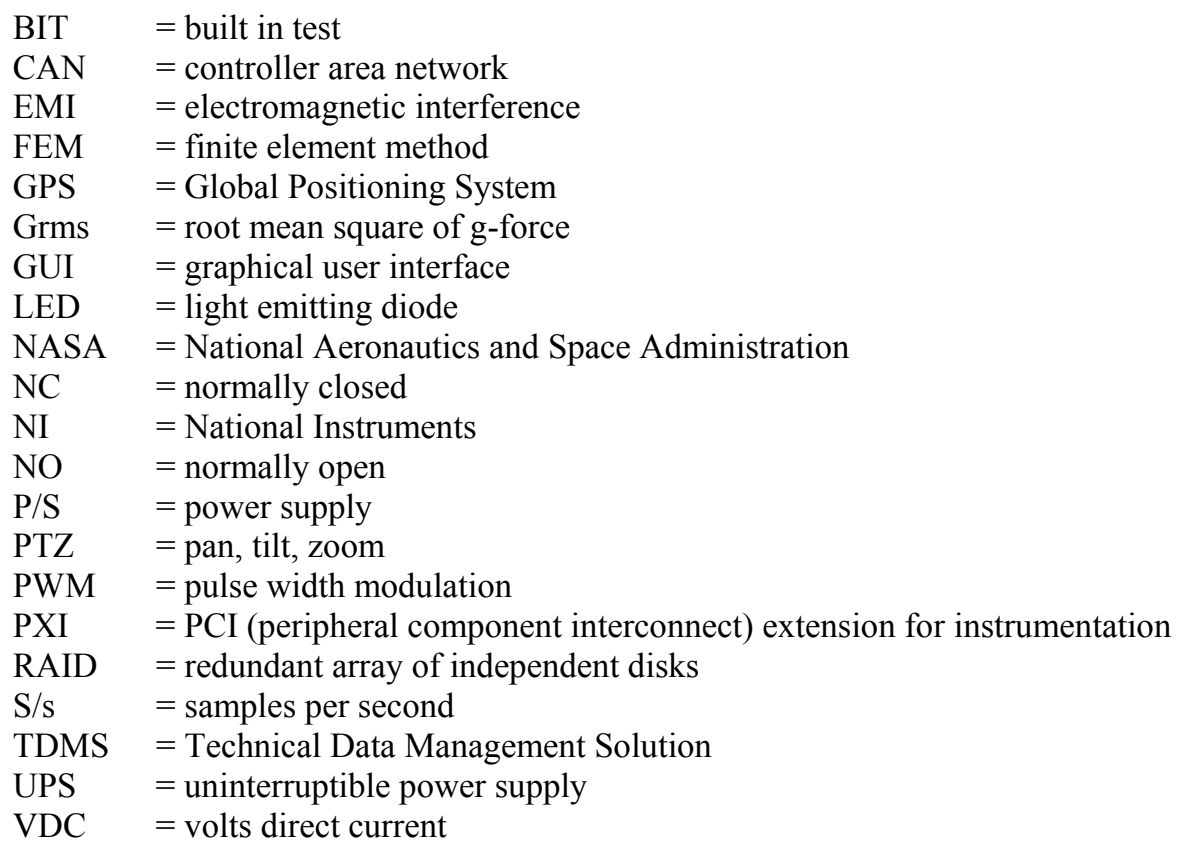

\section{Introduction}

A s battery and motor technologies advance, the realm of powered flight is expanding to include electric propulsion. A It is beneficial to gain a better understanding of such propulsion systems from electrical, aerodynamics, and structural perspectives. Steps toward that understanding are being implemented at the National Aeronautics and Space Administration (NASA) Armstrong Flight Research Center (Edwards, California) in the form of a modular electric propulsion test stand called Airvolt. The Airvolt test stand is designed to accommodate small systems on the order of $100 \mathrm{~kW}$ motors and propeller diameters up to $6 \mathrm{ft}(1.8 \mathrm{~m})$. Data acquisition systems monitor thrust and torque; currents and voltages between power sources, inverters, and motors; as well as vibrations, temperatures, and acoustic levels of the system. Measurement capabilities up to 2 million samples per second and bit resolution of 14 bits provide a valuable and unique capability and allow for better understanding of the system under test. The modularity of the

${ }^{1}$ Aerospace Engineer, Sensors and Systems Development Branch, P.O. Box 273 Edwards, California/MS4840D, AIAA non-member.

${ }^{2}$ Aerospace Engineer, Vehicle Integration and Test Branch, P.O. Box 273 Edwards, California/MS1013, AIAA nonmember. 
stand also allows for testing a variety of motor and inverter systems. The stand is designed to provide a means of accurately calculating efficiencies, reveal unknown dependencies between subsystems, and develop methods of verification and validation for new electric propulsion technologies. An overall layout of the Airvolt test stand can be seen in Fig. 1.

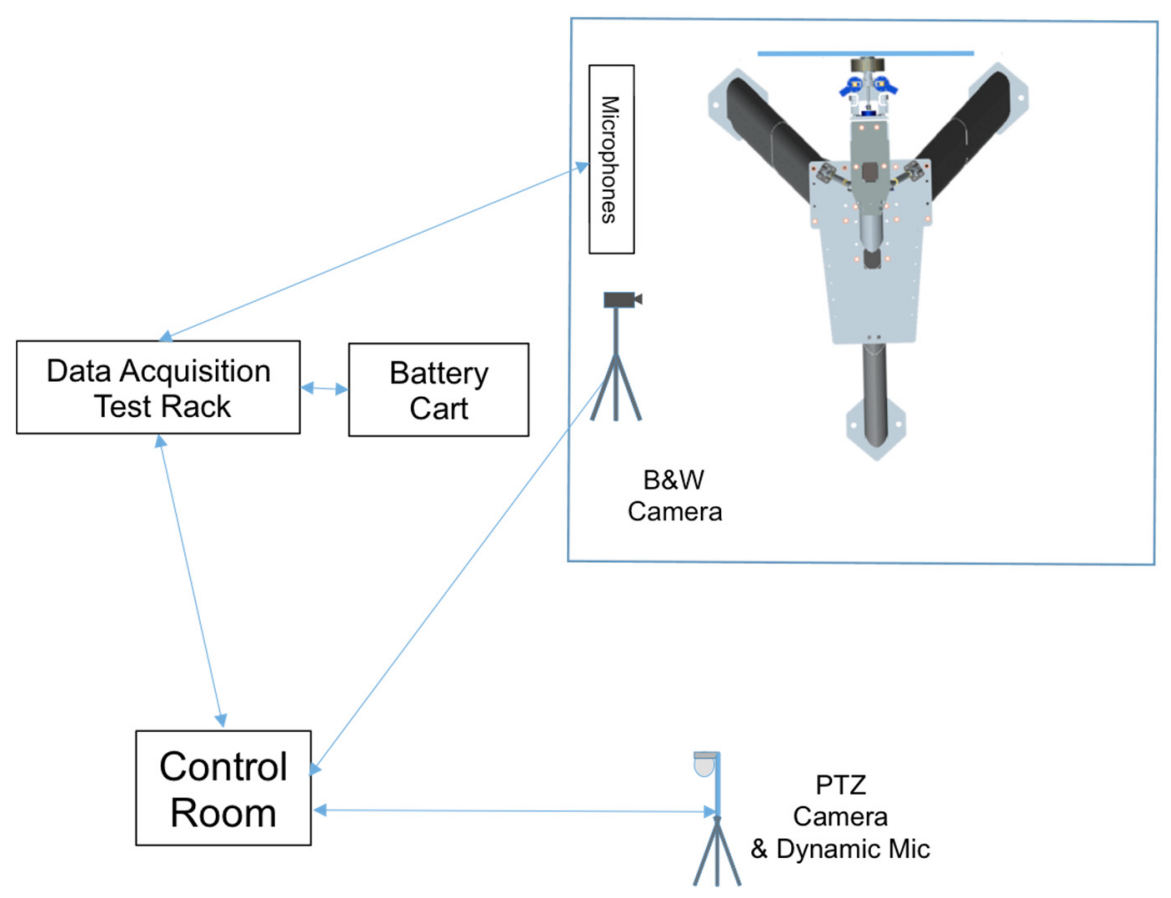

Figure 1. Airvolt test stand architecture.

\section{System Development Process}

\section{A. Test Article}

In the ideation phase of Airvolt, research into commercially available electric propulsion systems was performed. After beginning to understand the current state of the industry, requirements were set forth to determine the best way to test such systems, while allowing for flexibility and growth potential. As test stand development began, having an existing commercially available electric propulsion system provided a method by which the stand capabilities of the Airvolt test stand could be validated. Furthermore, having a known test article could help with troubleshooting and validating subsystems. The Airvolt test stand uses a Pipistrel Electro Taurus (Pipistrel, Ajdovscina, Slovenia) plug and play propulsor (See Bibliography item 1), which was selected for its high power to weight ratio. The specification of the system can be seen in Table 1, and the components of the system can be seen in Table 2. Three of these systems were purchased, which included the motor, inverter, and batteries.

Table 1. Pipistrel Electro Taurus Specifications.

\begin{tabular}{|l|l|}
\hline Electric motor & $\begin{array}{l}\text { Permanent magnet, air cooled, synchronous 3-phase } \\
\text { PWM 40kW (53hp max) 30kW continuous }\end{array}$ \\
\hline Max RPM & $2200 \mathrm{RPM}$ \\
\hline Battery voltage & $270 \mathrm{~V}$ \\
\hline Battery capacity & $7.10 \mathrm{~kW}$ \\
\hline System weight & $75 \mathrm{~kg}(165 \mathrm{lb})$ \\
\hline
\end{tabular}


Table 2. Pipistrel system components.

\begin{tabular}{|l|}
\hline 4 batteries \\
\hline Inverter \\
\hline $\begin{array}{l}\text { ESYSMAN V2 - Pipistrel's cockpit interface to control } \\
\text { the system }\end{array}$ \\
\hline High voltage module - measures the high voltage \\
\hline CAN bus ${ }^{1}$ communication module \\
\hline Battery charger \\
\hline Electric motor \\
\hline
\end{tabular}

\section{B. Sensors}

Research of commercially available systems and the Green Flight Café Challenge (See Bibliography item 2) led to specific sensor requirements. One of the main goals of the test stand is to measure efficiencies throughout the system, including motor and inverter efficiency. This efficiency can be derived by measuring the electrical power into and out of the inverter and the mechanical power coming out of the motor (Eq. (1) and Eq. (2)).

$$
\text { Motor }+ \text { Controller Eff }(\%)=\frac{\text { Pout }}{\text { Pin }}=\frac{\left[\text { Torque }(\mathrm{Nm}) x \boldsymbol{\theta}\left(\frac{\mathrm{rads}}{\mathrm{sec}}\right)\right]}{(\text { volts }) x(\text { amps })}
$$

\section{Motor and Inverter Efficiency}

$$
\text { Controller Eff }(\%)=\frac{\text { Pout }}{\text { Pin }}=\frac{\left(\text { volts }_{\text {in }}\right) x\left(\text { amps }_{\text {in }}\right)}{\left(\text { volts }_{\text {out }}\right) x\left(\text { amps }_{\text {out }}\right)}
$$

\section{Inverter Efficiency}

Power can be determined by using the following sensors:

- Voltage sensors (LEM CV 3-500);

- Hall effect current sensors (LEM LF 305-S);

- Load cells (Honeywell Model 45 and 47 for thrust and torque); and

- RPM feedback from the motor controller.

These high-bandwidth voltage and current sensors were selected due to the expected high frequency content resulting from pulse width modulation (PWM) the inverter uses to spin the motor. The load cells were selected because of their high measuring accuracy at the expected forces $( \pm 500 \mathrm{lbf}(2224 \mathrm{~N})$ at $0.04 \%$ accuracy $)$.

Other measurements include:

- Vibration through two tri-axial accelerometers installed near the motor mount interface;

- Temperatures of motor, inverter, batteries and data acquisition system;

- Atmospheric conditions (ambient temperature, static and dynamic pressure, wind speed, humidity); and

- Acoustic signature measured by microphone arrays.

The accelerometers are used as a safety measure to detect any excessive vibration or loading during motor and propeller operation. Similarly, the temperature sensors monitor the temperatures of the motor, inverter, and batteries to ensure that the temperatures do not exceed the safety limits set forth by the manufacturer. Measuring the temperature in the air-conditioned data acquisition rack allows assurance of data integrity. Since the data acquisition cards have specifications to operate within a preset temperature range, knowing the temperature during the test is necessary for post-processing.

After sensor selection, sampling rates were determined based on the parameter measured. The determined sampling rates can be seen in Table 3. A high sampling rate is especially necessary for the three phases coming from the inverter since the inverter uses transistors to switch current on and off to control motor speed. For the inverter selected, this switching happens at frequencies near $10 \mathrm{kHz}$; we chose sampling rates well over twice that rate. 
Table 3. Data sampling rates.

\begin{tabular}{|l|c|}
\hline \multicolumn{1}{|c|}{ Sensor } & Sampling ate (S/s) \\
\hline Voltage & 250,000 \\
\hline Current & 250,000 \\
\hline Thrust & 250,000 \\
\hline Torque & 250,000 \\
\hline Temperatures & 1,000 \\
\hline Microphones & 96,000 \\
\hline Pressure & 1000 \\
\hline
\end{tabular}

A diagram of electrical sensor locations can be seen in Fig. 2.

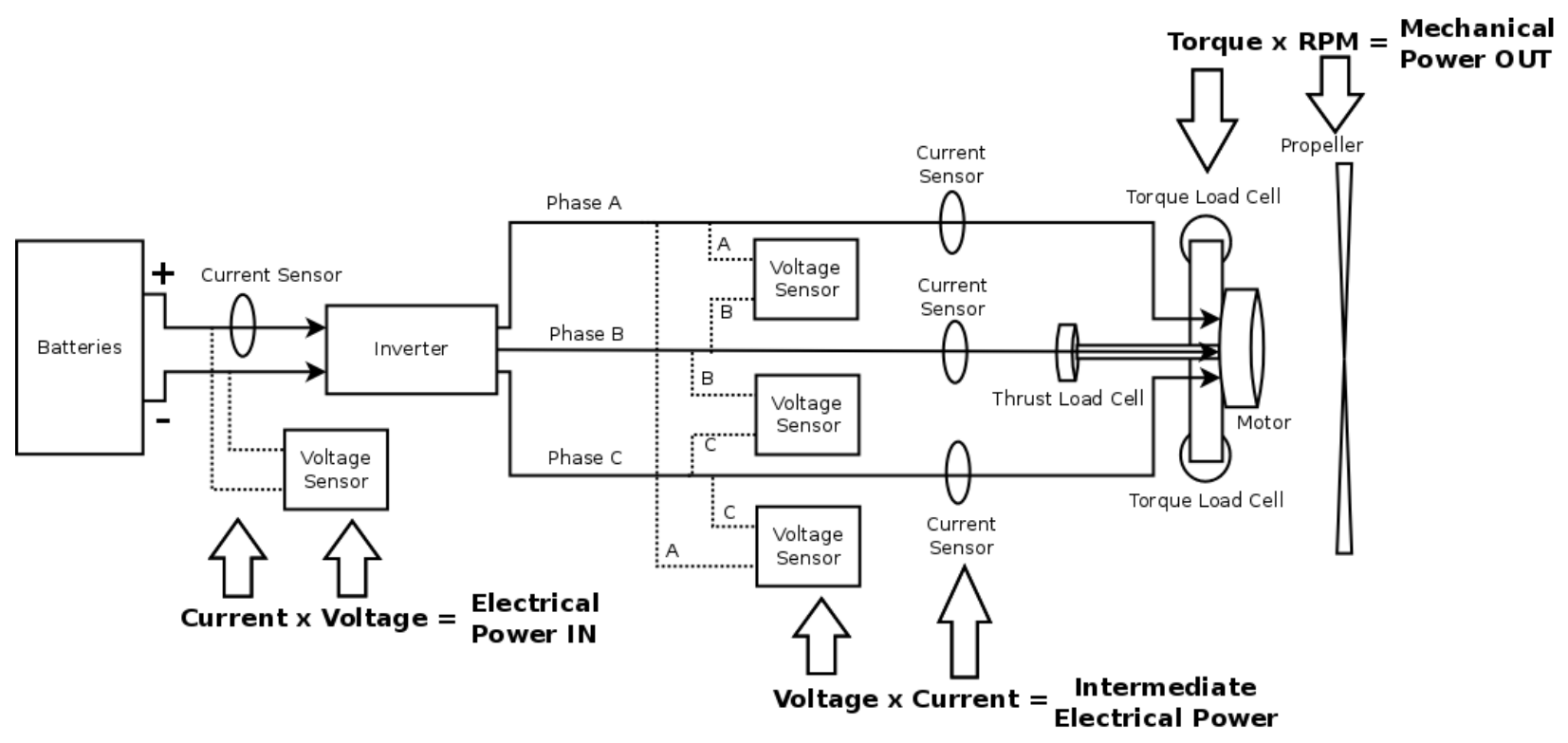

Figure 2. Sensor diagram.

\section{Testing}

Following preliminary decisions of the test article and sensor suite, a test plan was implemented to begin incremental testing of the system as it was put together. Figure 3 lays out the Airvolt test flow. 


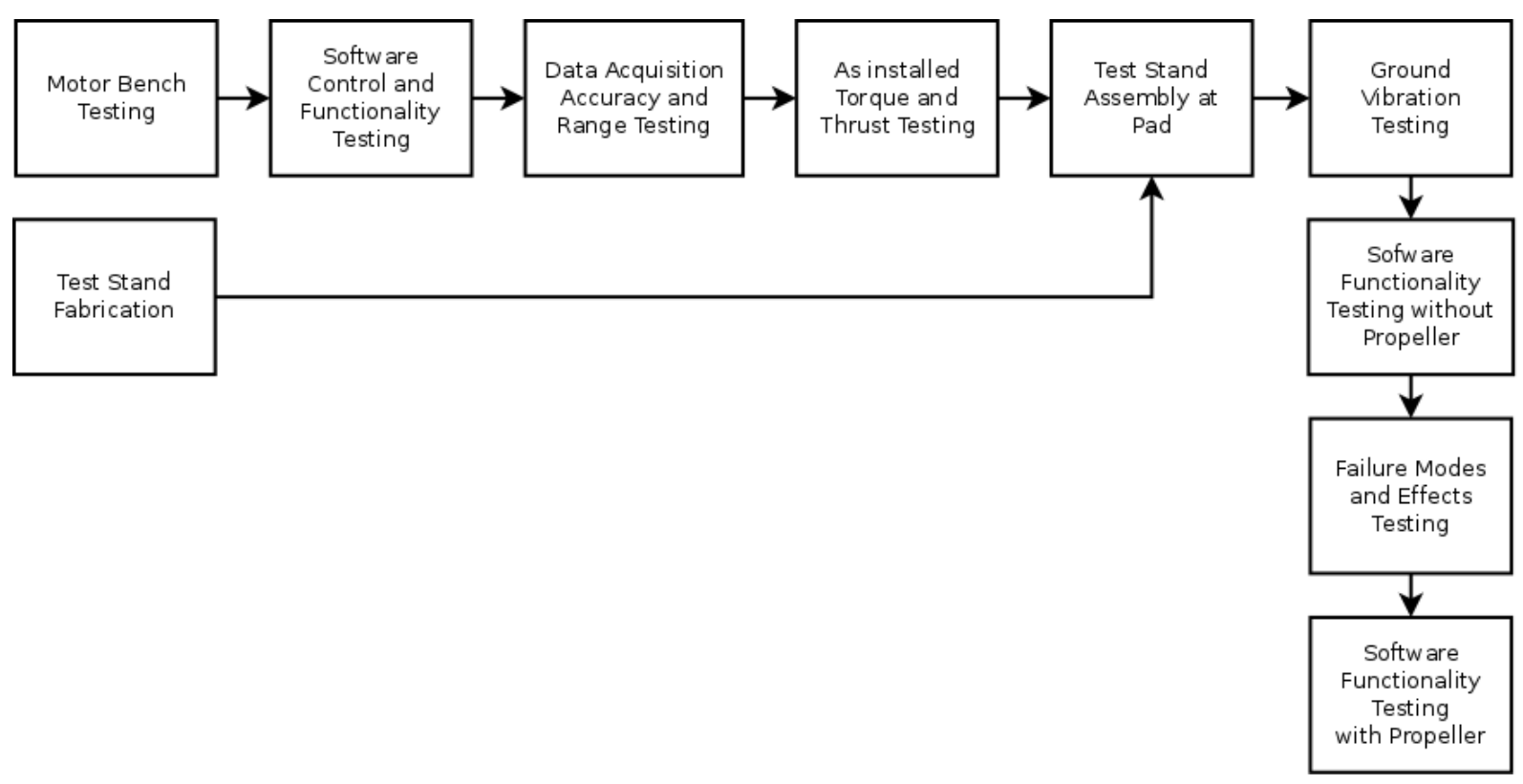

Figure 3. Test flow diagram.

This type of buildup approach efficiently integrates and verifies hardware and software prior to final installation. Two tasks, motor bench testing and test stand fabrication, took place in parallel. For motor bench testing a cart was used to support the motor and electronics (controller, inverter, and high-voltage module) shown in Fig. 4. Another cart was used as a battery cart as shown in Fig. 5. Two safety devices were implemented to ensure that power to the inverter could be quickly removed in case of an emergency. A box containing an emergency stop button and the lever on the enclosed switch box (Fig. 5) were used as safety devices. The first goal of the bench testing was to ensure the hardware worked using Pipistrel's pilot interface control (ESYS-MAN). Bench Testing also provided a way for NASA engineers to become familiar with the power system before controlling it using our software.

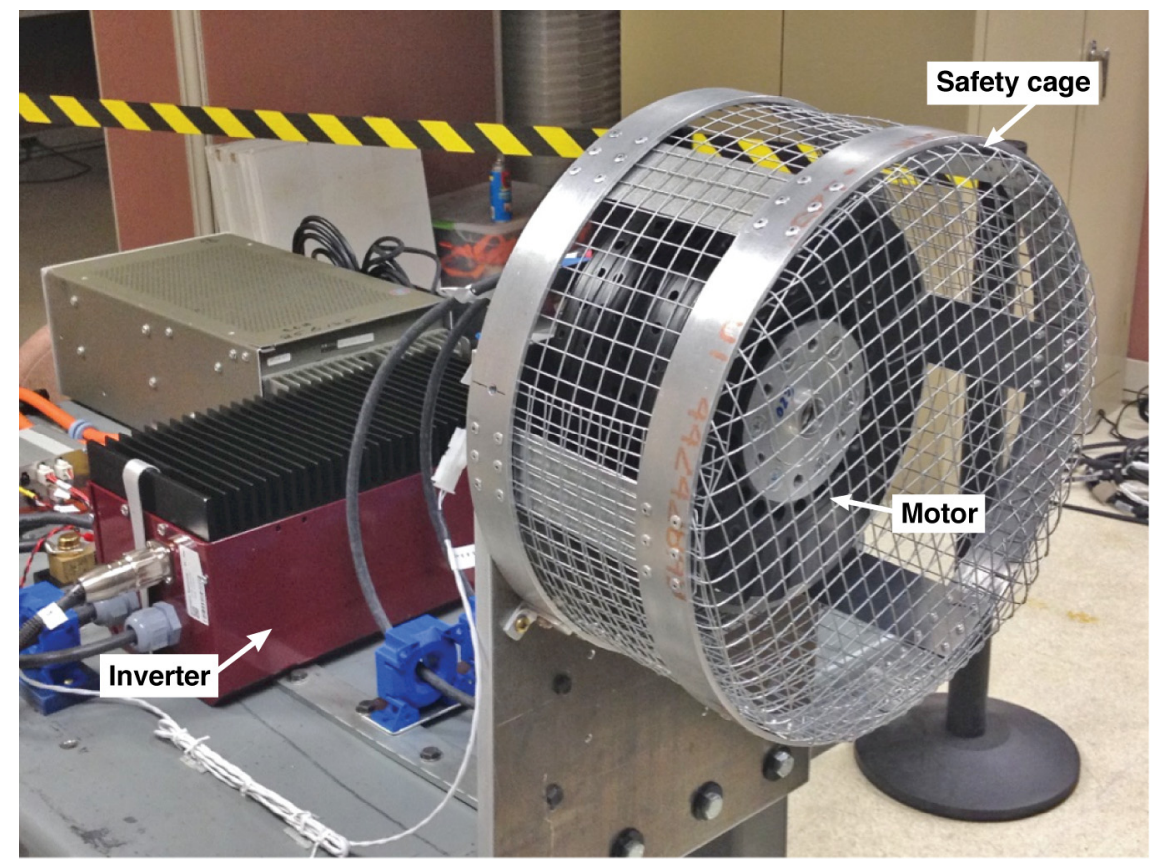

Figure 4. Bench testing cart 1.

American Institute of Aeronautics and Astronautics 


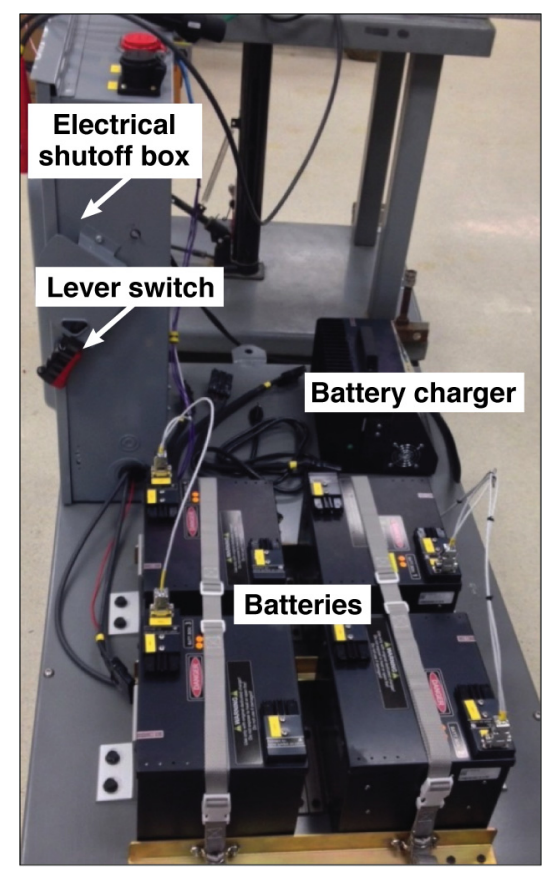

Figure 5. Bench testing cart 2.

\section{Data Acquisition and Control}

Concurrent with testing was buildup of the data acquisition and control software and hardware. Two computers are used for data acquisition and control. One computer in the control room (client) is used to call up the software of the computer used for data acquisition (server). The client also serves to display the data to the users in the control room and allows control of the article under test. The software used to program the client and server computers is National Instruments (NI) (Austin, Texas) LabVIEW (See Bibliography item 3). A list of the National Instruments data acquisition and control cards used can be seen in Table 4. The 6133 cards were selected for their high simultaneous sample rates ( 8 simultaneous samples at up to 2.5 million samples per second), and the 6289 card was selected for its large number of inputs and is used for data that do not require high sample rates.

Table 4. Data acquisition cards.

\begin{tabular}{|l|c|}
\hline \multicolumn{1}{|c|}{ Card number } & Data \\
\hline NI PXI-6683 & GPS signal \\
\hline NI PXI-6289 (18 bit sampling) & $\begin{array}{c}\text {-Sensor excitation } \\
\text { feedback } \\
\text {-Pressures }\end{array}$ \\
\hline NI PXI-6133 (14 bit sampling) & Voltage and current \\
\hline NI PXI-6133 (14 bit sampling) & Microphones \\
\hline NI PXI-6133 (14 bit sampling) & Accelerometers \\
\hline NI PXI-6133 (14 bit sampling) & Temperatures \\
\hline NI PXI-6133 (14 bit sampling) & Temperatures \\
\hline NI PXI-6133 (14 bit sampling) & Thrust and torque \\
\hline NI PXI-8512 & CAN bus \\
\hline
\end{tabular}

The data acquisition racks are two standard 19-inch racks that house the following:

- National Instruments data acquisition hardware;

- Storage drives;

- Sensor power supplies;

- Uninterruptible power supply (UPS);

- Signal conditioning circuits;

American Institute of Aeronautics and Astronautics 
- Test article manual operation hardware; and

- Air conditioning unit.

These racks are located close to the test stand to minimize cable lengths from the sensors to any signal conditioning and data acquisition cards. Data coming to the racks are stored as raw data (not converted to engineering units) at their full sample rate in a redundant array of independent disks (RAID) in Technical Data Management Solution (TDMS) format. The data is then converted to engineering units to compare with the user defined safety limits and sent to the control room at a slower rate. During development of the data acquisition code, it was noticed that requiring the data acquisition rack to transmit data to the control room at the full rate of sampling often meant that the data seen at the control was not near real time. Since the primary purpose of the data visualization at the control room is that of safety, not having near real time data is unacceptable. As a result, the data acquisition computer software is programmed to look at each data set it receives, find the data point that is closest to any safety limit, and transmit that point. The shortfall of choosing not to transmit at the full rate is the inability to see waveforms generated by the inverter in real time, which might aid in determining test points on the fly. Figure 6 shows an overview of the data acquisition and control flow.

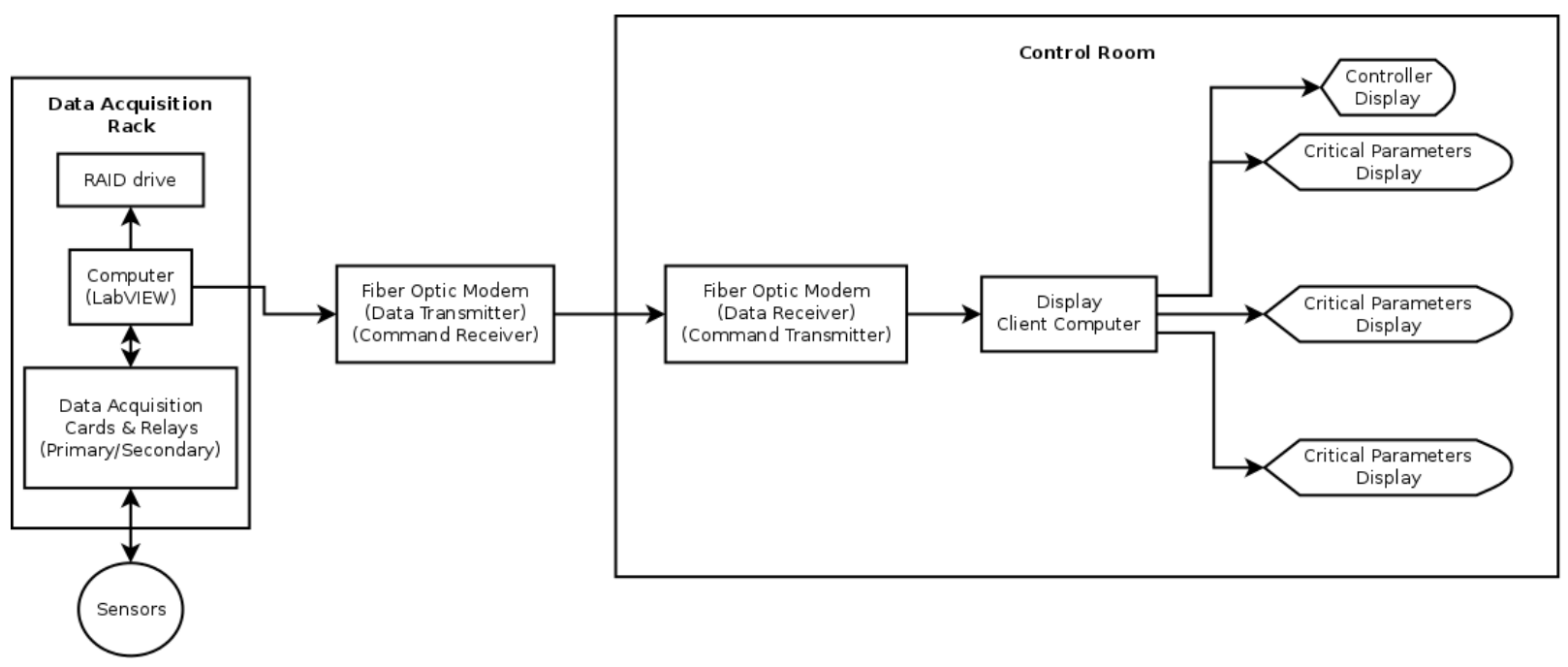

Figure 6. Data flow diagram.

After bench testing was complete, the control software being developed was ready for controller area network (CAN) bus ${ }^{1}$ functionality testing. The ESYS-MAN interface (Table 2) utilizes the vendor's proprietary CAN bus ${ }^{1}$ protocol to control and monitor the system. Power, battery life, RPM, and system temperature status are visible to the user on the interface. The ability to mimic these functions was required by the software so that a user inside a control room can remotely command and monitor the article under test. RPM commands can be sent through the control software via a graphical user interface (GUI) slider interface, or by executing a preprogrammed file that contains time based RPM commands for precise control. This type of command was made possible with the CAN bus ${ }^{1}$ message protocol provided by Pipistrel. For this test the control software interfaced with the bench test configuration using a National Instruments CAN bus ${ }^{1}$ interface card (Table 4). Initial testing only included reading the CAN bus ${ }^{1}$ messages in order to validate correct message interpretation. Some representative instrumentation was also incorporated so that the software could be tested for proper sensor data acquisition. Motor, inverter, and battery voltages and currents were measured. Following successful CAN bus ${ }^{1}$ monitoring, RPM control was demonstrated through a GUI. A jumper cable allowed for quick switching between ESYS-MAN control and software control for troubleshooting purposes.

\section{E. Sampling Synchronization}

Since one of the primary goals of having the test stand is to measure efficiencies accurately, it is necessary to gather data simultaneously. This simultaneous sampling is especially true when it comes to the output of the inverter, which switches current in the $\mathrm{kHz}$ range. In order to accurately determine power at a given moment, voltage and current need to be sampled at precisely the same time. Gathering all data in a synchronized manner also provides a 
better picture of what is happening at any given moment. As mentioned before, the 6133 cards are configured for simultaneous sampling of up to 8 channels. However, when gathering data from multiple different cards and microphone data from a separate data acquisition system, it is necessary to synchronize the data to a common reference. It was determined that the best reference for this task is Global Positioning System (GPS) time. As software development progressed it was evident that the 6133 and 6289 cards had different limitations on their ability to access the peripheral component interconnect (PCI) extension for instrumentation (PXI) back plane and GPS time tag of all of the data. As a solution, the clocks of all the data acquisition cards are replaced by the GPS time clock and a start trigger signal is sent through a dedicated timing circuit in the backplane of the PXI chassis. Since the GPS time is recorded when triggered and then the GPS clock is used to sample the data, it is acceptable to use the initial GPS recorded time and the change in time (delta $\mathrm{T}$ ) of the data acquisition cards to time tag the data during post processing.

\section{F. Stand}

Parallel with the data acquisition development was design and fabrication of the stand that supports the test article, sensors, and interconnecting cables. Initial iteration of the test stand was a truss-braced structure. Further consideration helped determine that the acoustic signature coming from air passing over the trusses, along with the aero loads by the cylindrical structures would cause errors in some of the measurements. As a result, the next and current iteration is a structure using square steel tubes with fairings to reduce the effects of aero forces on the structure. Figure 7 shows the dimensions and overall design of the stand.
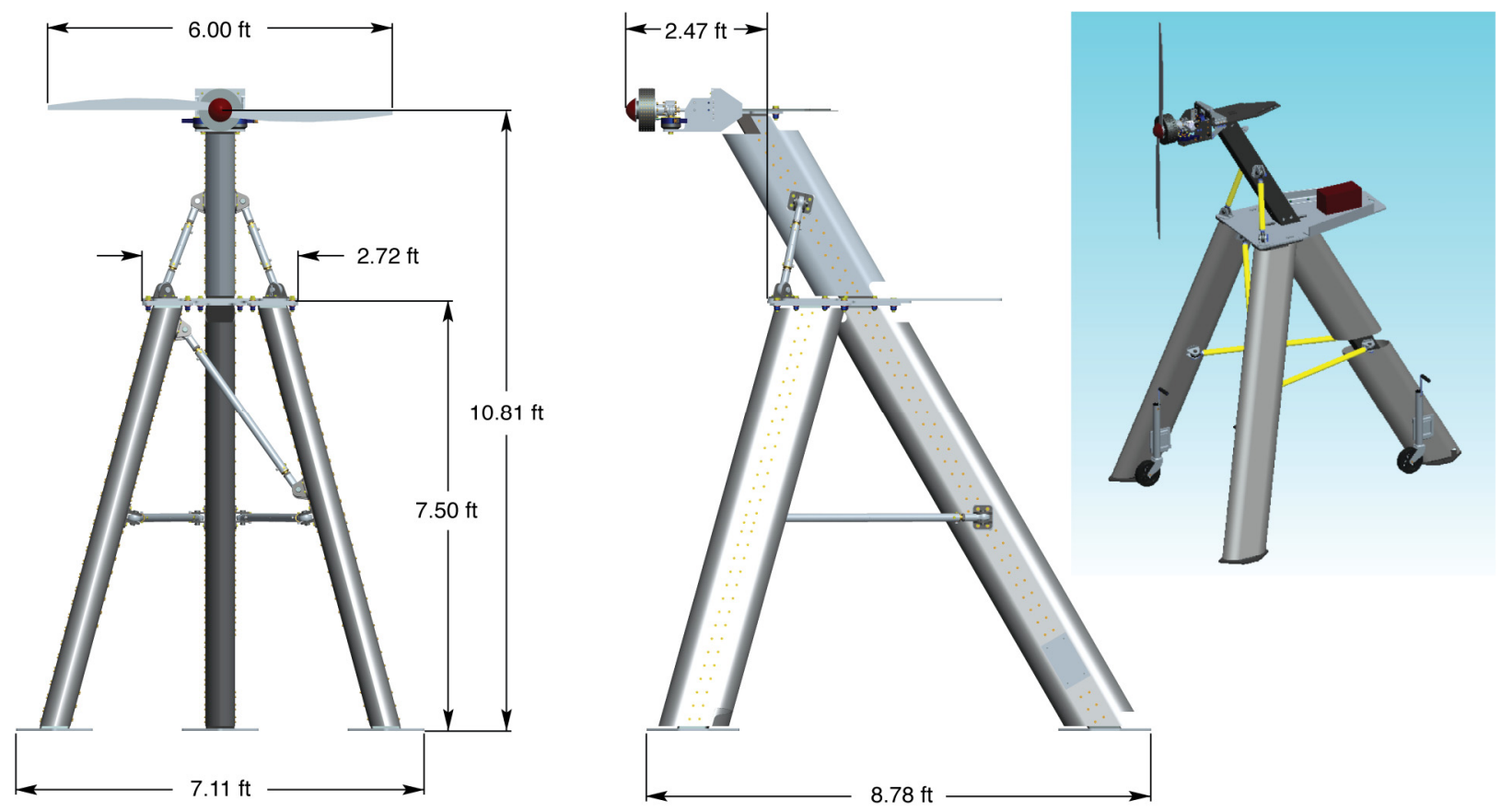

Figure 7. Test stand dimensions.

Another aspect of the stand that went through design iterations is the interface between the motor under test and the stand itself. Initial designs used a thin walled torque tube with strain gauges in order to better measure the torque of the motor and propeller. It was determined that the overhang weight of the motor acting at the end of the tube would create too large of a moment arm and a new iteration of the design resulted. The new design uses two load cells on either side of the motor with levers from the arm pushing and pulling on the load cells to derive torque. This configuration can be seen in Fig. 8. In this configuration, bearings are used to provide axial translation and rotational freedom while constraining all other degrees of freedom. Measuring thrust was initially thought to be more straightforward. A rod was used to connect the thrust load cell to the motor assembly. This assembly consisted of a motor adapter ring, a lever arm ring, and a pillow block for added stability. 


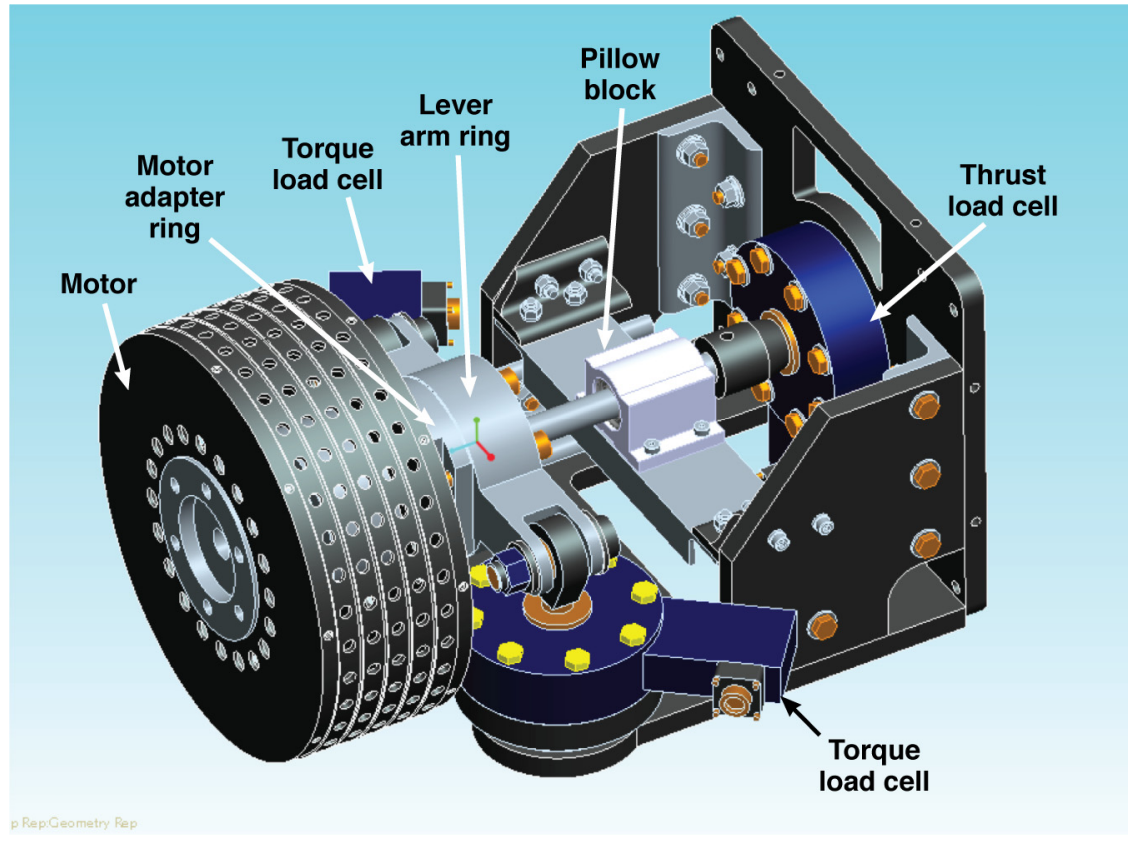

Figure 8. Motor/stand interface.

The modularity of the stand was also taken into consideration during the design. In order to allow for dynamic pressure testing of systems, the top section of the stand is a separate unit. An image of the upper section can be seen in Fig. 9. The wiring of the stand is also modular by having segmented wiring for each portion of the stand. Furthermore, the upper section of the stand can be mounted onto a cart, while the battery pack and the data acquisition racks are permanently mounted onto carts. This modularity allows for easier transportation of the various segments and in turn enables outdoor testing while protecting the equipment from adverse weather when not in use.

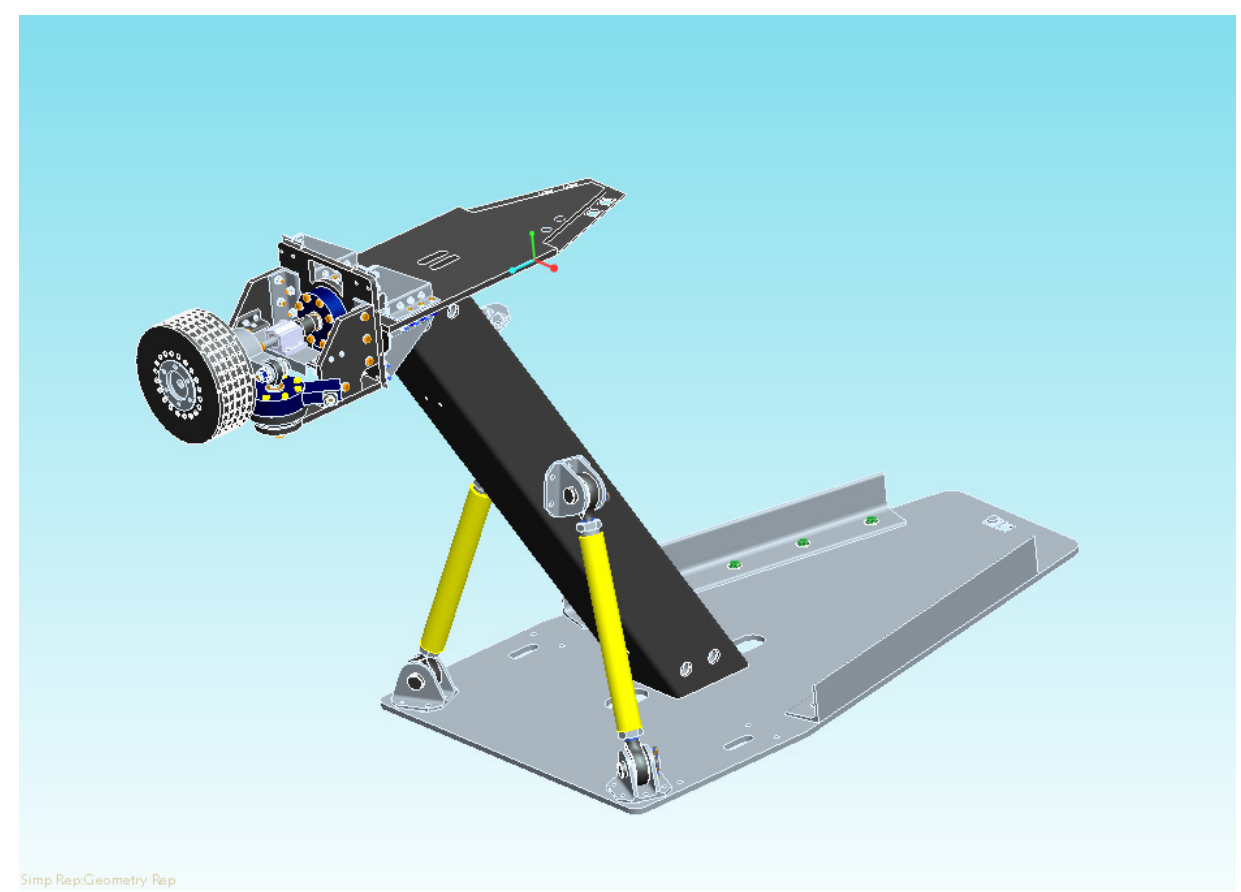

Figure 9. Test stand upper section.

American Institute of Aeronautics and Astronautics 


\section{G. Safety}

Testing of electric propulsion systems often means dealing with electrical power and physical hazards that need to be mitigated before testing. The largest mitigation executed by the Airvolt team was to locate the test pad in a remote location and to physically separate the test stand and the control room. The control room is located in a small building a hundred feet from the actual test stand. The control room provides physical safety for test personnel while using cameras and microphones to provide situational awareness of the test stand. Fiber optic cables from the test stand data acquisition racks provide data to the control room.

Electrical safety is improved by having three sets of safety contacts that must be activated before power can go to the motor. If any of the three safety mechanisms are tripped, power between the batteries and the inverter will be cutoff. The first safety switch is a lever switch located on an electrical shutoff box on the cart housing the batteries (Fig. 10). This switch connects the large conduits in the electrical shutoff box. The box also contains a high power contactor that needs to be closed to connect the path between the batteries and the inverter. This contactor is normally opened and closes its contact only when powered. The power supply to accomplish this is located in the control room in a Manual Power Relay Control box (Fig. 10). This box contains both a key switch and an emergency stop button. When the key is in the "on" position and the emergency stop button is in the disengaged position, power from the power supply is routed to the high power contactor through a relay in the data acquisition rack. Finally, the relay in the data acquisition rack is controlled through software and when engaged sends power from the power supply in the manual power relay control box to the high power contactor, which is then engaged and along with the manual lever switch on the electrical shutoff box, closes the circuit between the batteries and the inverter. A diagram of this setup can be seen in Fig. 10.

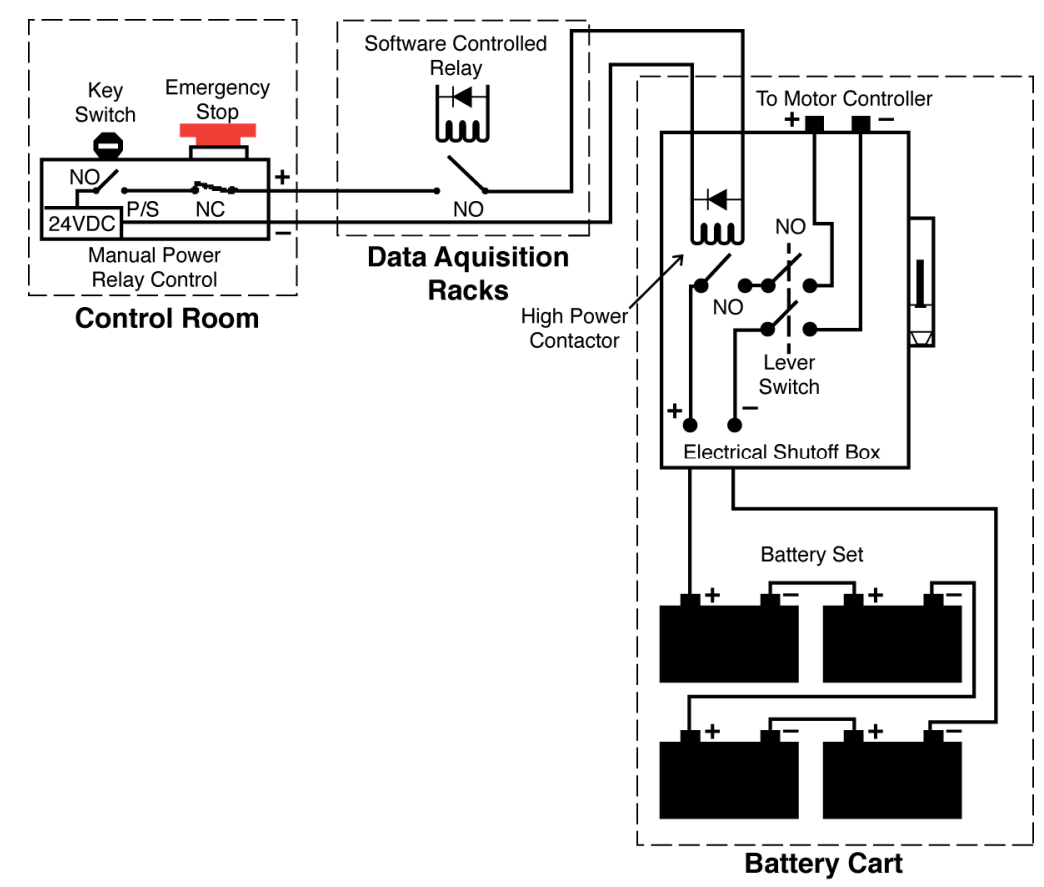

Figure 10. Safety interlock diagram.

To enhance the safety of the equipment once the test has begun, 2 triaxial accelerometers are used to measure vibrations in the three axes. These values are monitored and if they exceed user defined Grms (root mean square of G-force) limits, they will automatically open the software controlled relay and stop the test. This form of automated shutdown also exists on other safety critical parameters such as:

- Battery voltage;

- Battery current;

- Battery temperature; and

- Motor temperature. 
In case of power loss to the control room or the data acquisition racks, two UPSs are used. One UPS for the data acquisition racks and one for the control room computer. These power supplies allow for enough backup power to safely shutdown the system in the event of facility power loss.

\section{H. Software}

National Instruments LabVIEW is used for the data acquisition and control of the system under test. These functions are done largely using the concept of queues. In LabVIEW, queues are used to organize data or processes in sequence. In this context, it is used to take data from multiple sources and pipeline them for processing and streaming. Although better architectures might exist, queues were selected initially to make the software robust against changing parameters and sensor suites. The software logic diagram for the server computer in the data acquisition rack can be seen in Fig. 11.

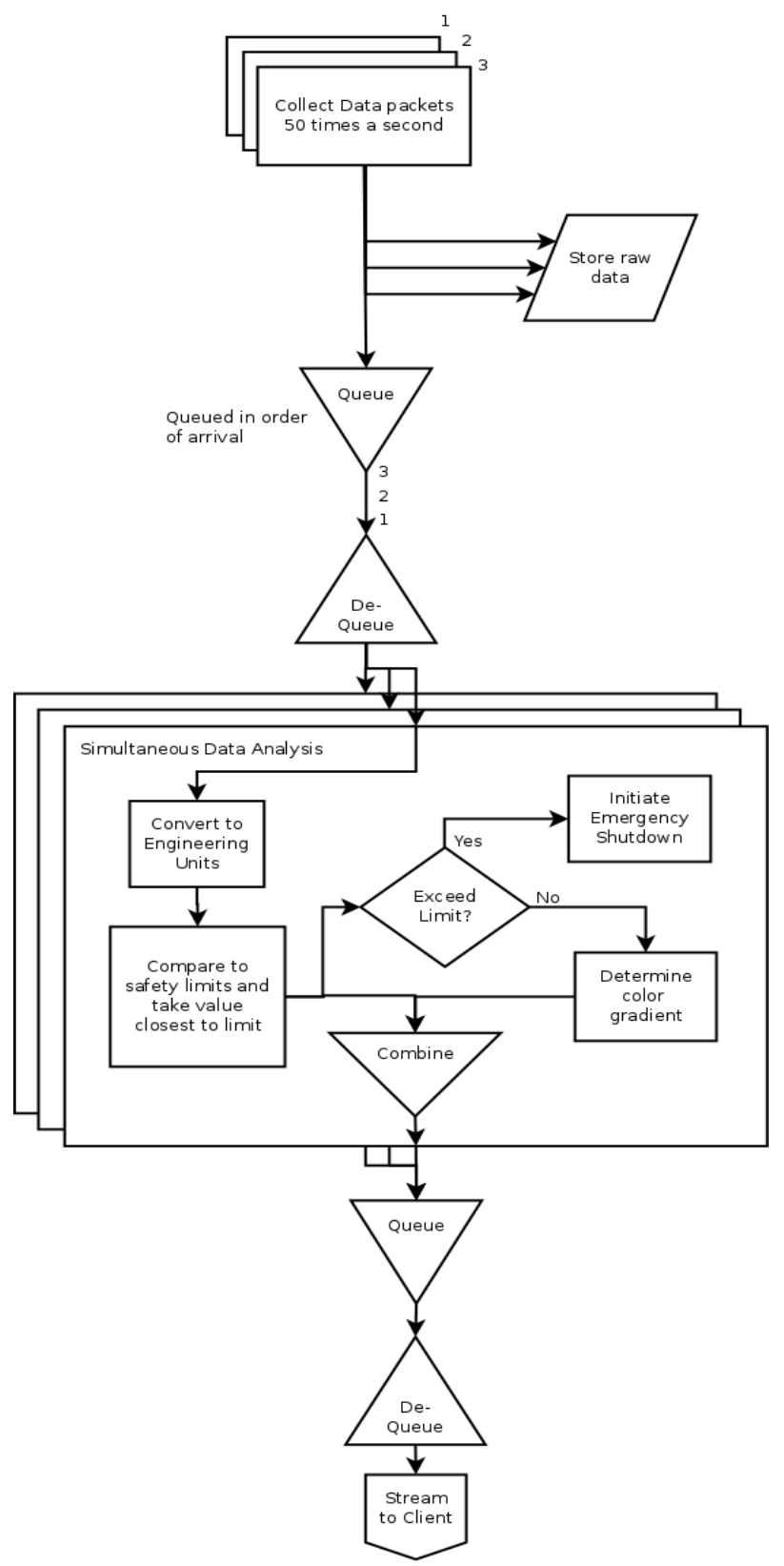

Figure 11. Software logic diagram for server. 


\section{Data Collection}

The software collection section executes the following:

- Collect a set of data 50 times a second.

- Simultaneously store data in a TDMS file format, and use sensor identifiers to put the data in a shared queue.

\section{Data Analysis}

The data analysis portion runs simultaneous instances of the following:

- Take one set of data from the queue.

- Use the sensor identifier to determine which sensor collected the data. Use that information to determine the calibration equation for that piece of data.

- Use the calibration equation to convert the data into engineering units.

- Use the sensor identifier to determine the safety limits and compare the data to the limits.

- Find the data point that is closest to any safety limit.

- Use the proximity to a safety limit to determine a color gradient between green and red. If the data point has passed the red safety limit, initiate emergency shutdown.

- Send the sensor identifier, color gradient value, and data point to a queue that goes to the streaming section of the code (if emergency shutdown is not initiated).

\section{Data Streaming}

The data is streamed by taking a value from the queue and sending it to the control room computer which is also running a separate set of LabVIEW code. The receiving computer takes the bundle information and puts it in a queue that is sent out for parsing. The software logic for the receiving computer in the control room can be seen in Fig. 12.

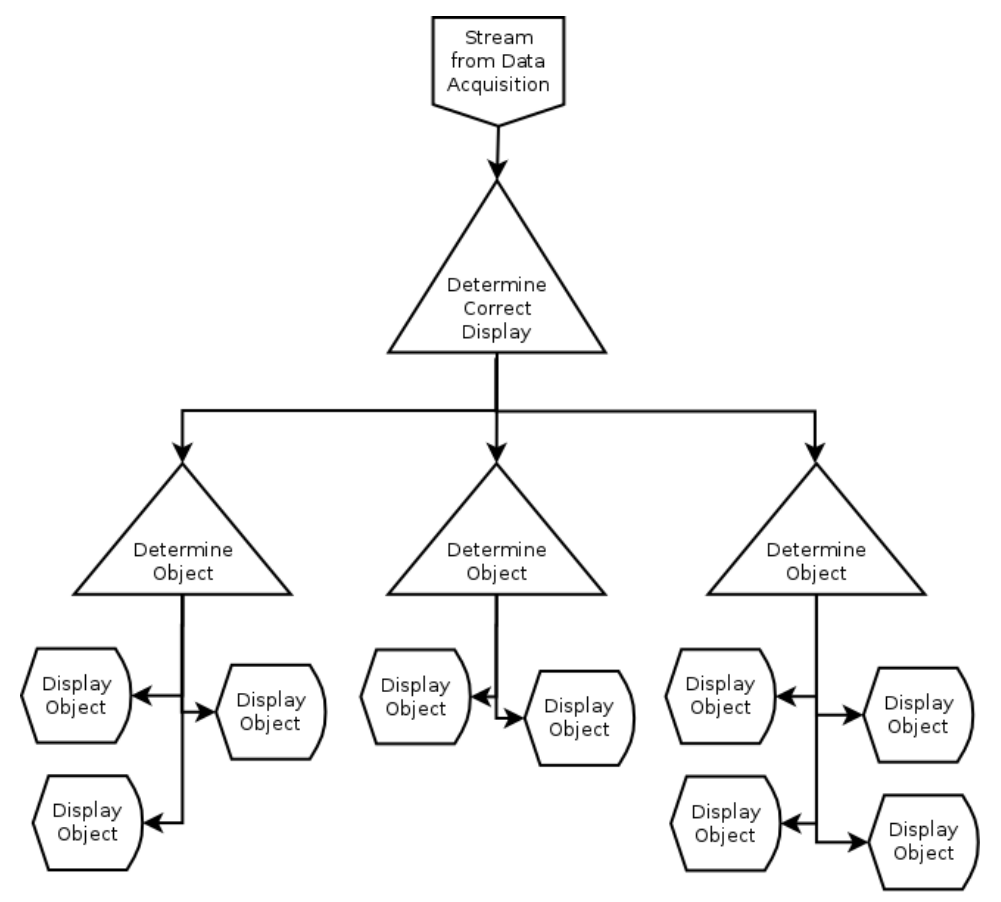

Figure 12. Software logic diagram for client.

\section{Data Dissemination}

User-defined information and the sensor identifiers are used to determine which of the three monitors receives the data. Since the streaming function brings in the data in the order it was received, the software looks at each piece of 
data and determines its final destination. Once the data is received by the portion of code that is dedicated for each monitor, the code then uses the sensor identifier to determine which specific display object the data point needs to go to.

\section{Data Display}

Once the data is sent to the display object, the object displays the data point and also updates a color light attached to the display object. The intent is to provide better situational awareness to the user by providing large color light that show a gradient between green and red. The color lights are used for each display object so that a non-green color will draw the user's attention quickly to the sensor in question and also let the user know how close a parameter is to the safety limit. An example of a display can be seen in Fig. 13.

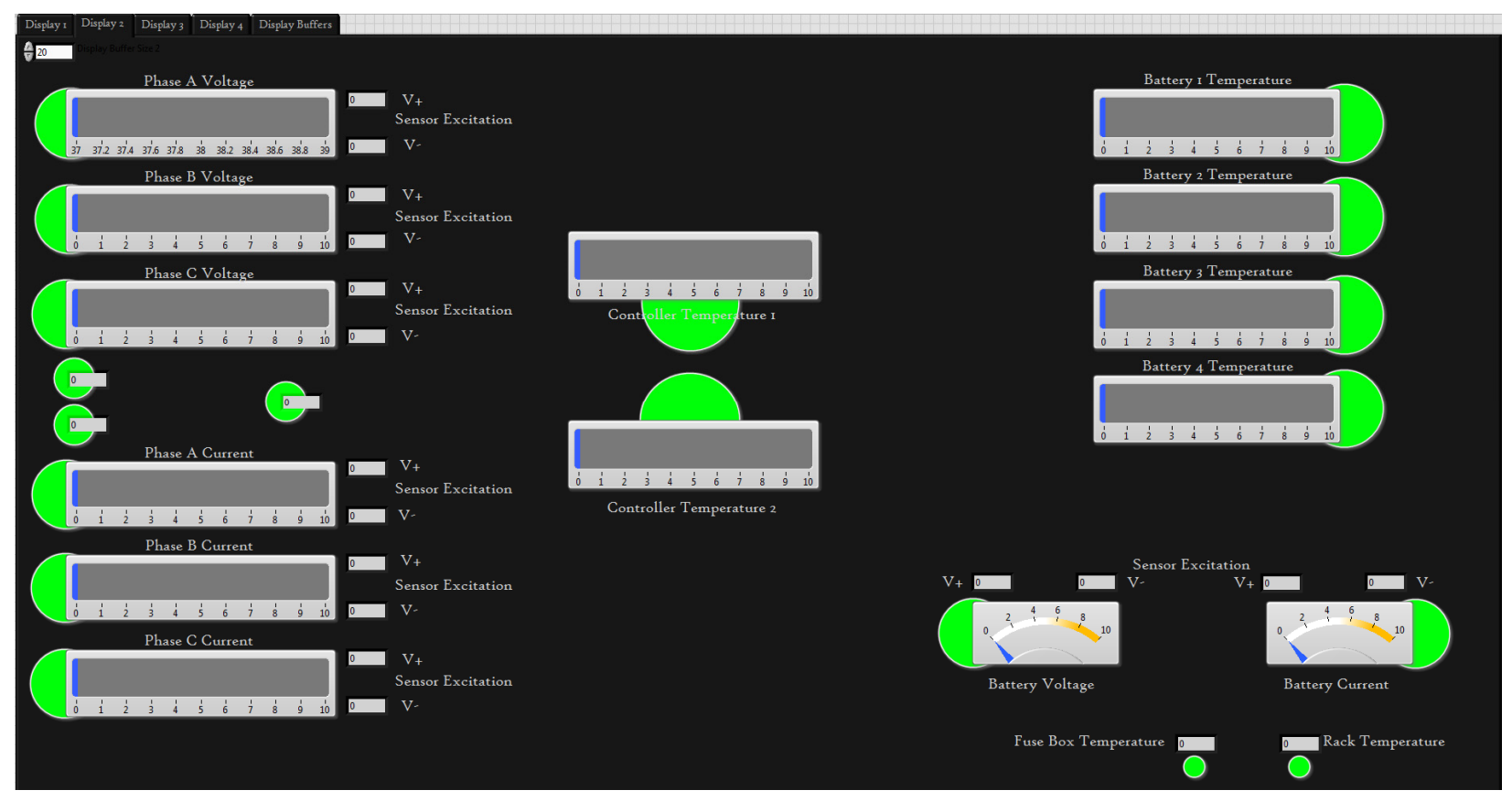

Figure 13. Display of sensor data.

\section{Software Control}

Software control is executed in a similar fashion by using queues to send commanded values to the data acquisition rack, which uses software to convert the commands to CAN Bus ${ }^{1}$ messages that go to the inverter or go directly to NI cards to control the relays. Figure 14 shows the software logic for control. 


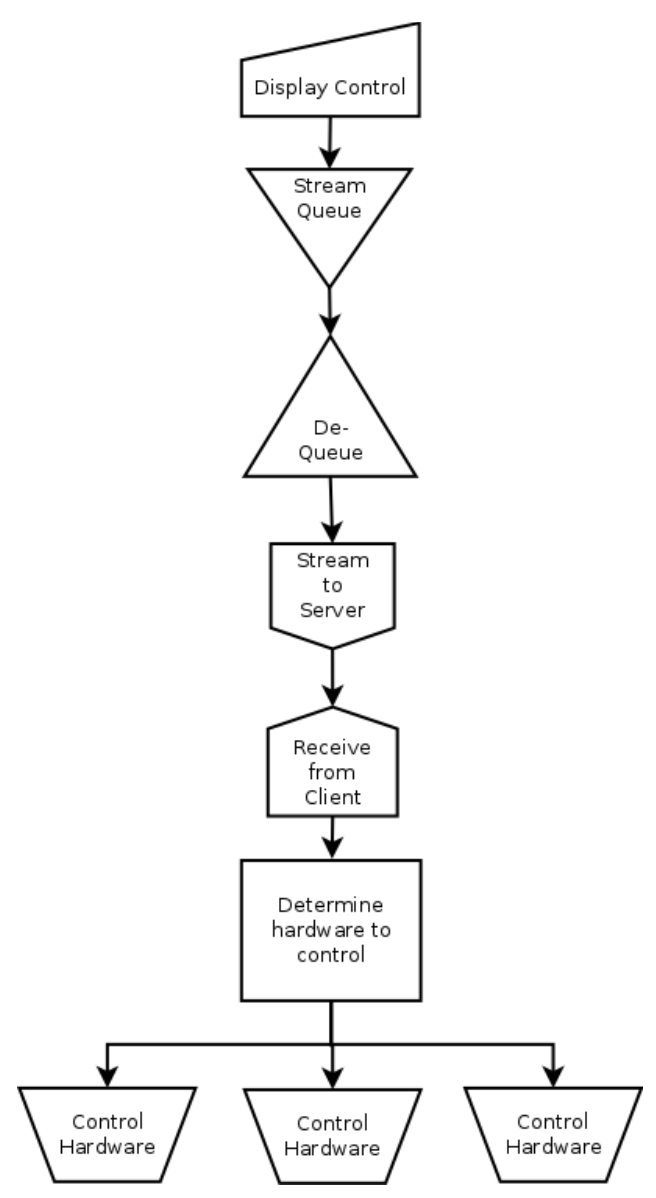

Figure 14. Software logic diagram for control.

Automated Emergency shutdowns are conducted by running a piece of code on the data acquisition side that opens all the relays and then gracefully reverts the running software to a safe configuration. Emergency shutdowns commanded by the user are done by simultaneously doing the following:

- Putting the emergency shutdown command at the front of the queue going to the data acquisition rack.

- Remotely starting the emergency shutdown code at the data acquisition rack.

If the data acquisition rack notices that the connection with the control room computer has been severed, it automatically performs an emergency shutdown as well.

The capability to run the motor along a pre-determined RPM profile also exists. By selecting a file that contains the RPM commands and the duration times, the software can execute a precise test profile.

\section{Built in Test (BIT)}

The software also contains the capability to conduct a built in test (BIT). This BIT is not performed on the article under test directly. Instead the software itself is evaluated to ensure:

- Integrity of the calibration coefficients file;

- Real time data display;

- Reported values within the safety limit without motor power; and

- Reported values within the safety limit with the motor running a benign test profile.

\section{A. Testing the Airvolt Stand}

After initial fabrication of the upper section of the stand (Fig. 9), further testing and hardware/software integration was conducted in the lab. This testing included software functionality and accuracy testing. Refer to Fig. 3 for the test 
flow. The motor, thrust and torque assembly, and sensors were installed onto the upper section. Full-length cables were connected to ensure testing included actual wire lengths of the final configuration (Fig. 15).

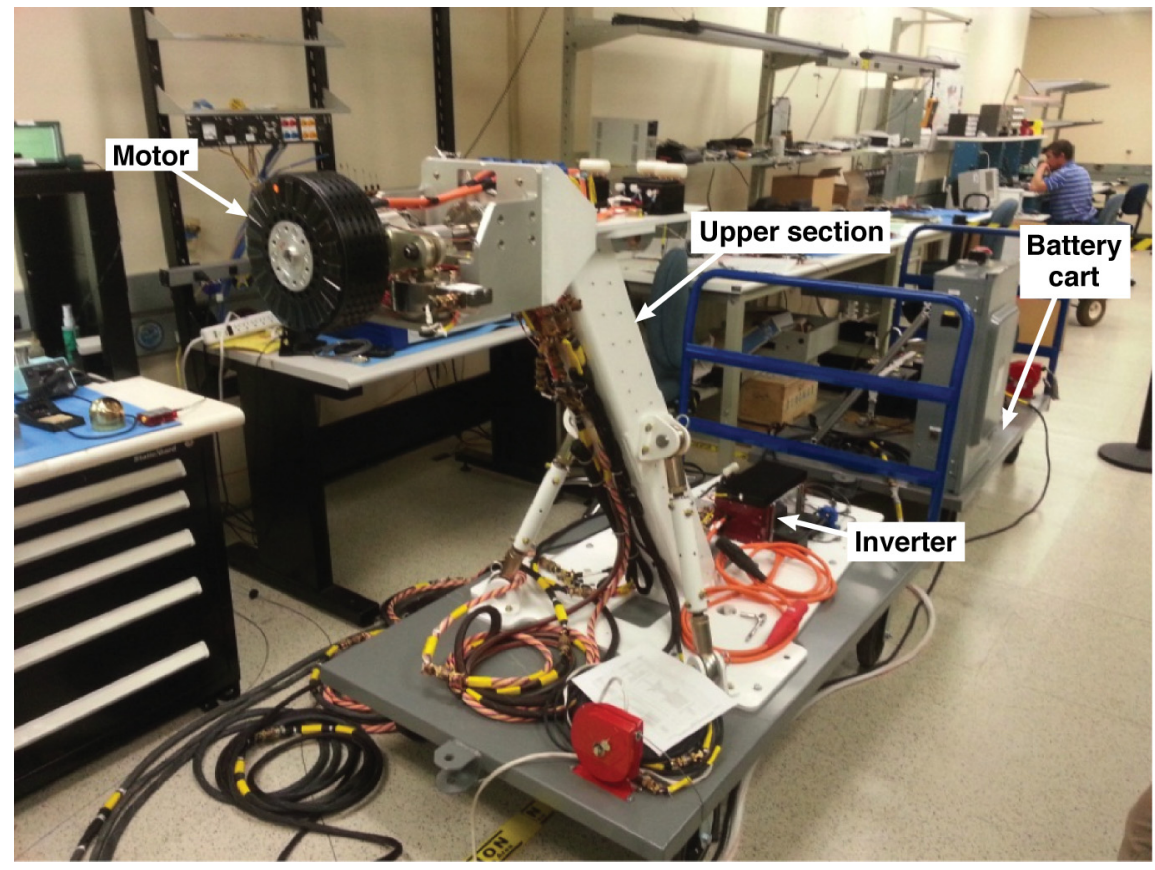

Figure 15. Upper section configuration.

During initial integration in the lab, the motor on the upper section was placed in close proximity to the test racks containing the signal conditioning and data acquisition cards. Upon energizing the motor, large noise spikes of $0.5 \mathrm{VDC}$ were observed on almost all sensor channels with the exception of CAN Bus ${ }^{1}$ data. Grounds and cables were inspected, to ensure that all twisted shielded wires were properly terminated and tied to earth ground. No cable fabrication issues, or ground loops were found. After some troubleshooting, it was decided to move the motor/gooseneck 20 feet away from the data acquisition racks, so that the test rack was behind the motor. This step noticeably reduced the large noise levels in the data, but did not completely eliminate the noise that exists while the motor is powered on.

The software and hardware testing included verifying automated motor shutdown functions upon exceeding critical parameter limits, as well as software checksum integrity, display color changes, sensor excitation voltages, and the overall health of the system. All GUI objects and functions were verified, such as the throttle slider for setting motor RPM and the ability to load in preprogrammed RPM commands for precise automated testing. Another test performed was the accuracy of each data acquisition input channel. A source voltage was provided using an accurate calibrator, and a 6 digit voltmeter was used to verify that each input channel was reporting values within the manufacturer's specification.

Since it was not possible to safely operate the system with the propeller rotating inside an electronics lab, a simple test setup was devised to apply known load to the thrust and torque load sensors while monitoring the values through the LabVIEW ${ }^{3}$ software. For thrust, a threaded rod was connected to a calibrated force gauge on one end and fastened to the propeller mounting holes via a circular adapter. The force gauge assembly was rigidly secured using two beams connected to the side of the stand (Fig. 16). By manually rotating the motor, the threaded rod would impart known, pure thrust loads onto the motor and thrust/torque force balance assembly. This method allowed for testing of the configuration of the thrust load cell. Calibration loads were applied in $10 \mathrm{lbf}$ increments. It was discovered that the pillow block, which is a secondary support structure for added rigidity, was causing binding on the thrust measurements. The pillow block was removed and the thrust error decreased to about $6 \%$ for the configuration. Probable causes were friction in the total system, as well as inaccuracies with the lead screw alignment with the rest of the test apparatus. 


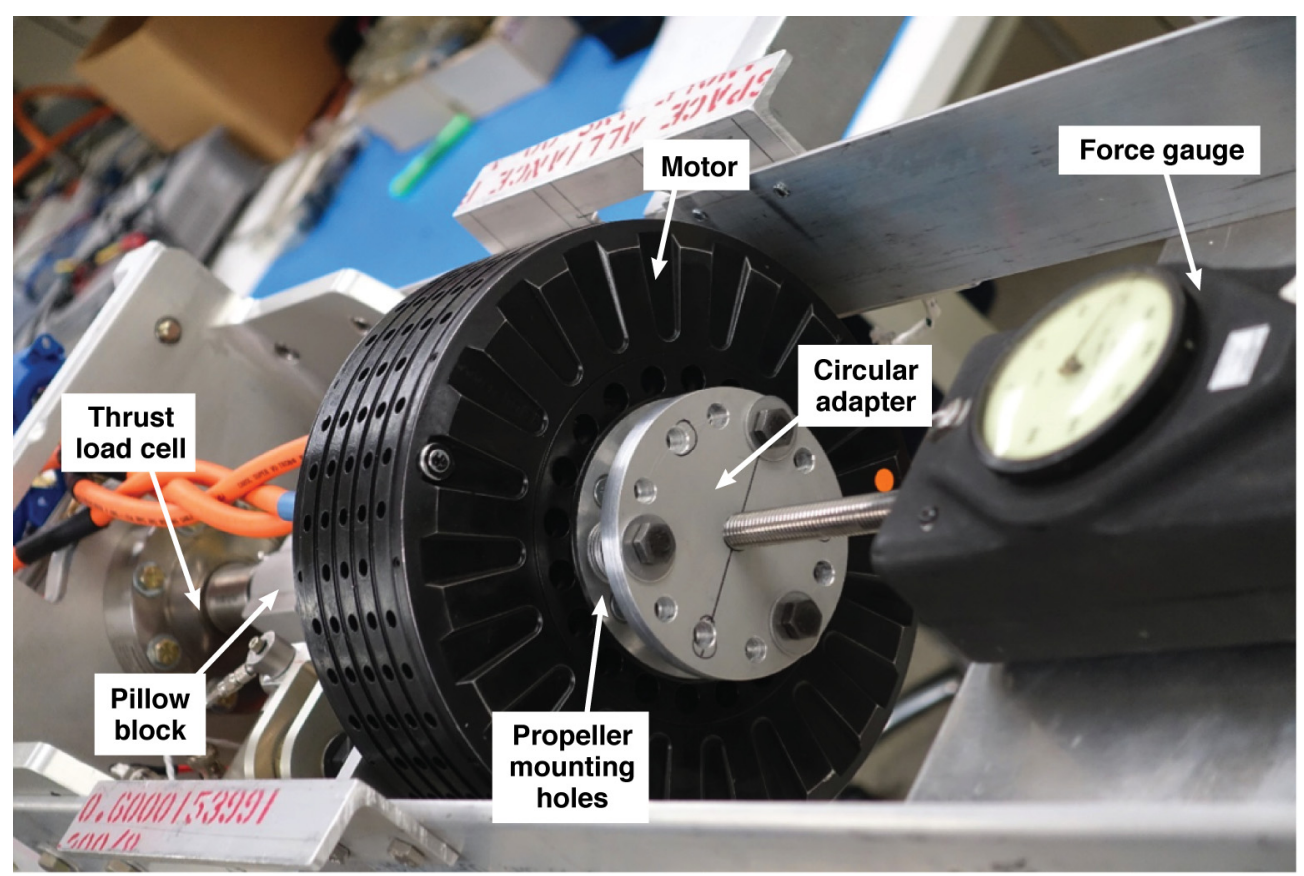

Figure 16. Thrust load cell testing.

For testing the torque assembly, two long lever arms were fabricated and attached to the motor adapter ring. On one arm a calibrated force gauge was mounted to a rigid lift table. On the other arm, calibrated weights were hung at the same radial distance as the calibrated scale (Fig. 17). Ten-pound weight increments were added to one side of the arm and the rigid lift table was lifted until the calibrated force gauge was applying equal, but opposite vertical loading. This method provided a pure torque loading while eliminating vertical force. Torque testing showed accuracies within the required $+/-1 \%$.

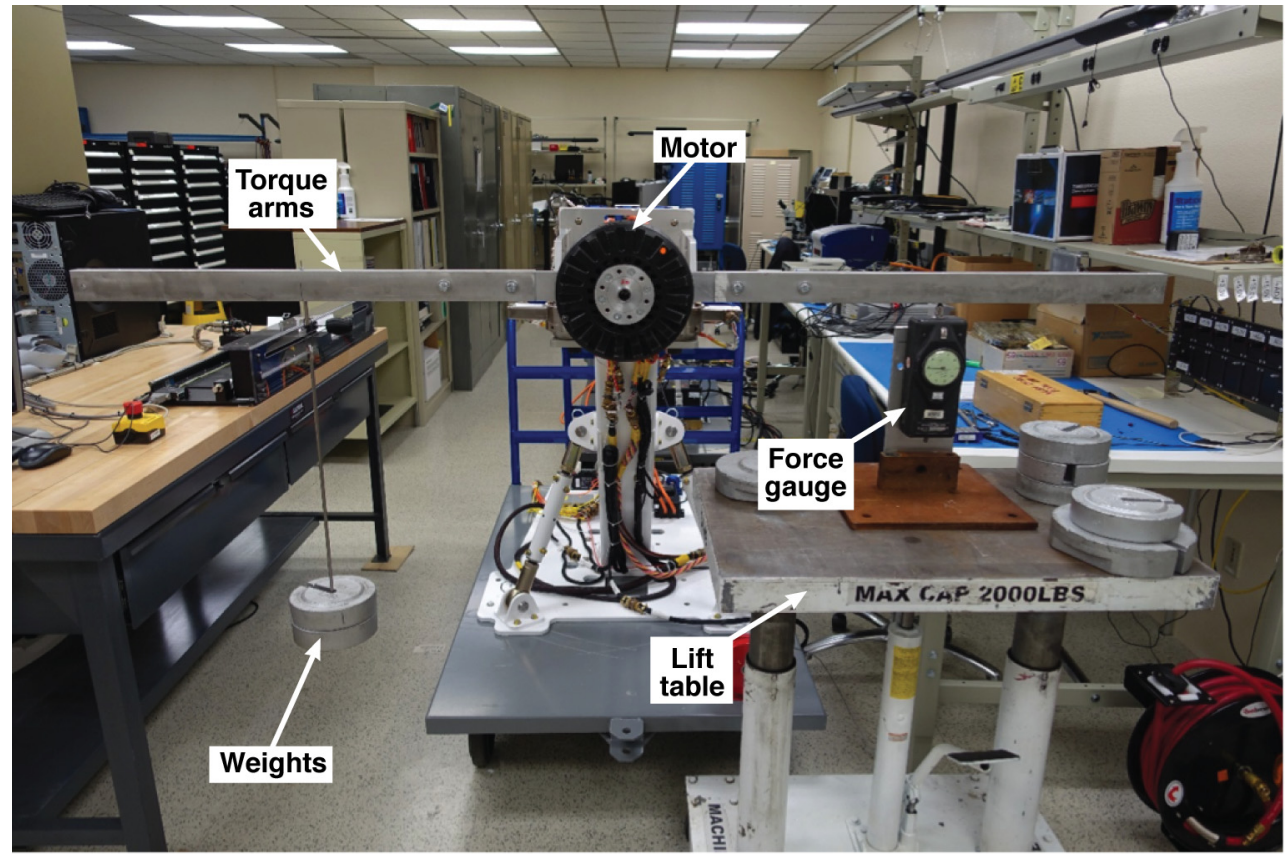

Figure 17. Torque load cell testing.

American Institute of Aeronautics and Astronautics 
Further testing with this setup included combinations of applied thrust, torque, and vertical forces to investigate potential mechanical crosstalk in the system. Mechanical crosstalk refers to unforeseen forces experienced by a load cell that differ from the applied forces. This crosstalk comes from the mechanical force balance that is created to isolate the loads. Investigations of this manner reveal problems in the setup or changes in calibration that can be applied to remove the effects of mechanical crosstalk.

After load cell testing was completed, the upper section was ready to be mated to the tripod legs for a fit check. The mechanical fit check was done in the flight structures high bay and allowed the engineers and mechanics to develop the most efficient approach for lifting the neck onto the legs. Straps were installed on lift points located on the stand, and a forklift was used to lift the gooseneck onto the legs. When the fit check was completed, the gooseneck was removed, and final software testing was performed.

\section{B. Control Room and Test pad}

With the software ready, the control room and pad site were prepared. The control room is configured with 4 monitors and one large LED TV screen. The monitors are used by the client computer for control and monitoring of critical data, and the LED screen is used for displaying video of the pad for situational awareness. A $20 \mathrm{ft}$ by $20 \mathrm{ft}$ concrete pad was poured at the test site to provide a solid foundation to mount the test stand. Pad construction also included putting in a ground ring and two ground terminals to which the system can be grounded. One point, tilt, and zoom (PTZ) camera allows the area to be surveyed and monitored. A fixed black and white camera is used to focus on the motor. The video is fed back to the control room using video baluns that allow long cable lengths without significant loss of picture quality. A dynamic microphone is used to monitor the motor for audible situational awareness. The dynamic mic signal goes through a preamplifier circuit and is transmitted via a balun to a receiver and a pair of speakers in the control room. Due to the seasonal winds in the area, a synthetic fur based windscreen is used to effectively cut down on wind noise.

\section{Pad Integration and Testing}

The upper section and tripod legs were assembled at the pad, and a ground vibration test was performed to determine the natural modes of the structure. This test helps impose restrictions on motor RPM dwell time if the fundamental frequencies are excited and also helps gather data for the finite element method (FEM) modeling so that when new motor assemblies are integrated and tested, natural modes can be obtained through simulation instead of requiring additional testing. The stand was tested using shakers positioned at strategic mechanical interface points with the Pipistrel test article in place. The motor assembly was then removed as shown in Fig. 18.

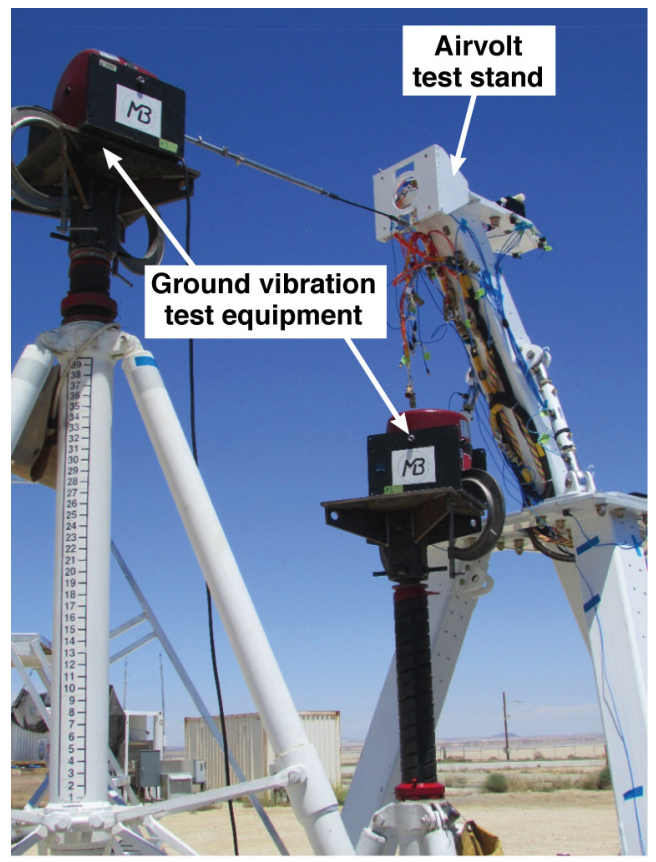

Figure 18. Test stand ground vibration testing. 
For full stand functionality testing, the test article system was exercised without the propeller, and the motor was taken to 2200 RPM. Electromagnetic interference (EMI) was encountered during motor power on, and created enough noise to set off automated shutdown prematurely. It was decided that testing would continue using manual monitoring and by explicitly going into a special debug mode in the software that bypasses the auto shutdown. The software was demonstrated to work as long as the automated shutdown logic was disabled. While not a permanent fix, it allowed testing to continue. Additional checks such as manual lever switch and power relay shutdown were tested, as well as certain failure modes such as the facility power loss simulation which verified the uninterruptable power supply functionality at the test rack and control room.

Following the failure modes and effects checkout, the propeller was installed in order to provide loading to the thrust and torque sensors.

Figure 19 shows the pad setup with the propeller and the relative distance of the data acquisition racks and the stand ( $\sim 25$ to $30 \mathrm{ft})$. From testing, it was evident that EMI noise can cause the sensors to be excessively noisy or biased. As part of the troubleshooting, the test rack was placed in various positions to attempt mitigating the EMI problem. Further testing is being performed at NASA Armstrong Flight Research Center to fully check the Airvolt sensor suite in order to validate the test stand and further learn how to mitigate the EMI issue.

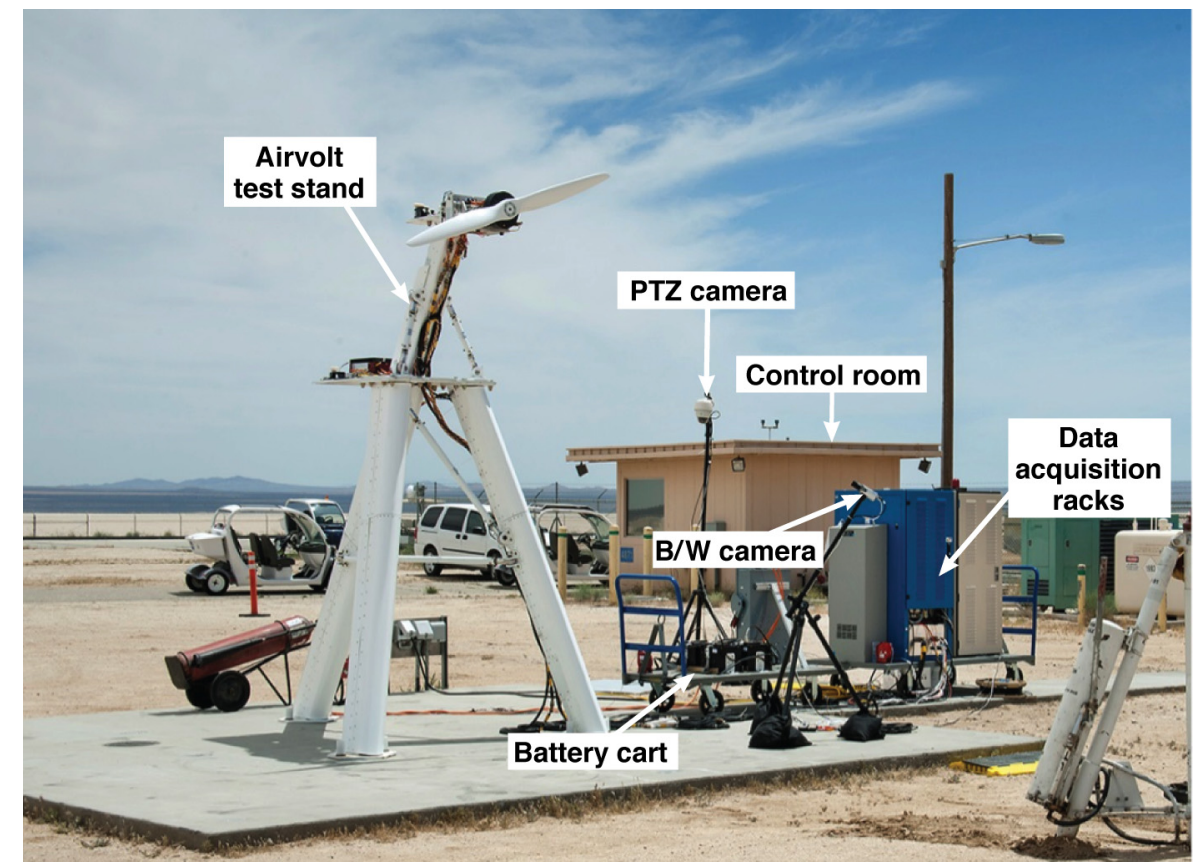

Figure 19. Test stand with propeller at test pad.

\section{Lessons Learned}

\section{A. Test Approach}

Following a test approach of building up and testing pieces independently aided in successful final integration, troubleshooting in a subsystem/component level helped identify and resolve issues before integrating the whole system. This build up method improved chances of success of the final product and also enabled personnel to become more knowledgeable of the system. Using hardware representative of the final configuration in a lab setting, allowed issues to be revealed early in the development process.

\section{B. Software}

Along with testing the hardware early at a subcomponent level, it was beneficial to test the software as it was being developed. Testing software with components of the hardware aided in learning to interface the software and hardware. Using representative hardware also revealed issues relating to the automated shutdown in terms of electrical noise pollution. 


\section{Electromagnetic Interference}

Although EMI mitigation strategies were considered at the initial stages of design, including standard electrical connection practices and instrument shielding, preliminary testing data indicates the presence of large EMI. Current investigations are focused on methods of EMI mitigation.

\section{Load Cell Testing}

Load cell testing conducted in the lab was valuable in identifying errors in reported values. Although the load cells themselves were calibrated, it was necessary to do a test to investigate mechanical cross talk between the load cells. This testing was also beneficial in identifying areas of friction that were absorbing some of the load and not transferring it directly to the load cell. This investigation led to the removal of the pillow block and improved measurements.

\section{Conclusion}

The availability of a high fidelity test stand is necessary to better understand electric propulsion systems. The Airvolt test stand attempts to establish a standard for testing these systems. Investigating state of the art electric propulsion systems and developing a test stand to accommodate future discoveries creates a foundation for the stand. Incremental testing of sensors and software, paired with incremental integration and testing can lead to a more successful final product. Electromagnetic interference is an issue that needs to be investigated in depth and mitigated in the early stages when dealing with electric propulsion systems. The magnetic fields generated by the motors and high power systems can cause many measurement problems and can be higher than expected even with standard EMI mitigation practices in place. The Airvolt electric propulsion test stand still needs to resolve issues relating to EMI and will begin collecting data on these systems. Data collected using the stand will be used to aid in more complex architectures, and in developing strategies and processes for integrating and instrumenting these systems on aircraft.

\section{References}

${ }^{1}$ Robert Bosch GmbH, “CAN Specification Version 2.0,” URL: http://www.boschsemiconductors.de/ media/pdf_1/ canliteratur/can2spec.pdf [cited 22 June 2015].

\section{Bibliography}

1) http://www.pipistrel-usa.com/electric/elec.html [cited 22 June 2015].

2) http://cafefoundation.org/v2/gfc_main.php [cited 22 June 2015].

3) http://www.ni.com/labview/ [cited 22 June 2015]. 